Mariya Zarichkova, Doctor of Pharmaceutical Sciences, Associate Professor, Department of Management and Economics of Pharmacy, Institute for Advanced Training of Pharmacy Specialists of National University of Pharmacy, Zakhysnykiv Ukrainy sq., 17, Kharkiv, Ukraine, 61001

E-mail: zarichkova@ukr.net

Diana Zoidze, PhD, Associate Professor, Department of Management and Public Administration, National University of Pharmacy, Pushkinska str., 53, Kharkiv, Ukraine, 61002

E-mail: management@nuph.edu.ua

UDC 615.322+582.94+581.9(477)

DOI: 10.15587/2519-4852.2021.225767

\title{
COMPARATIVE STUDY OF PHENOLIC COMPOUNDS OF THE HERB OF BETONICA L. GENUS SPECIES OF FLORA OF UKRAINE
}

\author{
Iryna Sas, Andriy Grytsyk, Taras Koliadzhyn, Oleh Koshovyi
}

Species of Betonica L. genus are widespread in Ukraine and contain different groups of biologically active substances: hydroxycinnamic acids, flavonoids, tannins, iridoids, terpenoids, steroids, essential oil, organic acids, vitamin K, nitrogen-containing compounds, phenylethanoid glycosides. Species of Betonica L. genus show a wide range of pharmacological activity (anti-inflammatory, antioxidant, choleretic, diuretic, sedative, antitumor, antihypertensive, etc.) and phenolic compounds are one of the most important and promising groups of biologically active substances of these plants.

The aim. The aim of the work was to conduct a comparative study of the phenolic compounds of the herb of Betonica L. genus species of flora of Ukraine.

Materials and methods. The object of the study was the herb of Betonica peraucta and Betonica brachydonta harvested in the phase of mass flowering of the plant in Ivano-Frankivsk region. The study of phenolic compounds was carried out by paper chromatography, HPLC and spectrophotometry.

Results. 7 components of tannins, 4 flavonoids, 5 hydroxycinnamic acids, 2 coumarins were identified and quantified by HPLC in the studied raw material. The quantitative content of the main groups of phenolic compounds in the herb of Betonica peraucta and Betonica brachydonta was determined by the method of absorption spectrophotometry: polyphenols $-5.96 \%$ and $4.82 \%$, tannins $-1.62 \%$ and $0.68 \%$, flavonoids $-2.07 \%$ and $1.13 \%$, hydroxycinnamic acids $7.01 \%$ and $3.58 \%$, respectively.

Conclusions. As a result of the conducted studies it was found that the content of phenolic compounds in the herb of Betonica peraucta is significantly higher than in the herb of Betonica brachydonta. Therefore, this species is promising for further research and creation of new drugs

Keywords: Betonica peraucta Klokov, Betonica brachydonta Klokov, herb, phenolic compounds, HPLC, spectrophotometry

(C) The Author(s) 2021

This is an open access article under the CC BY license (http://creativecommons.org/licenses/by/4.0).

\section{Introduction}

Species of the Betonica L. genus are widespread in Ukraine, they contain different groups of biologically active substances (BAS) and have a diverse pharmacological effect. The raw material base of Betonica L. species is sufficient, and at the same time these plants can be cultivated in soil and climatic conditions of the Carpathians. This indicates the prospects for the use of Betonica raw materials for the development of new herbal drugs.

Raw materials of the genus Betonica L. contain a wide range of BAS: hydroxycinnamic acids and their derivatives, flavonoids, tannins, iridoids, triterpenoids and steroids, carotenoids, essential oil, organic acids (including ascorbic acid), vitamin $\mathrm{K}$, nitrogencontaining compounds (including alkaloids). Nitrogen- containing compounds of Betonica are represented by betaine, trigonelline, and the alkaloids betonicin, stachidrine, betonite and choline. Betonica contains phenylethanoid glycosides represented by six compounds of similar structure named betoniosides A, B, C, D, E, F and by acetoside. Among the terpenoids linalool, ocimene, phellandrene and terpinene are found as well as sesquiterpenoids cadinene, cadinol, caryophyllene, diterpenoid betonicolide and its glycoside betonicoside $\mathrm{B}$ [1-5].

There are numerous data on studies of the chemical composition of species of the genus Betonica L. growing in Japan, the Republic of Kosovo, Hungary, Montenegro, Romania, Bulgaria, Lithuania, Poland, the Balkans [1, 2, 4, 5]. However, the chemical composition 
of species of the genus Betonica L. growing in Ukraine has not been studied enough.

Analysis of scientific sources also indicates that species of the genus Betonica L. show a wide range of pharmacological activity (anti-inflammatory, antioxidant, choleretic, diuretic, sedative, antitumor, antihypertensive, etc.) [5-10]. Phenolic compounds are one of the most important groups of BAS of these plants. Therefore, it is important to conduct the comparative phytochemical studies of phenolic compounds of the aboveground parts of two species of the genus Betonica L. growing in Ukraine, namely Betonica peraucta Klokov and Betonica brachydonta Klokov.
The aim of the work was to conduct a comparative study of phenolic compounds of the herb of Betonica L. genus species of flora of Ukraine.

\section{Research planning (methodology)}

Analysis of scientific publications indicates that the chemical composition of Betonica L. genus species of flora of Ukraine has not been studied enough [1-10]. Since phenolic compounds provide the pharmacological action of the plant it was decided to conduct an in-depth study of this class of compounds and to choose a more promising species for further research. This study included 5 stages (Fig. 1).

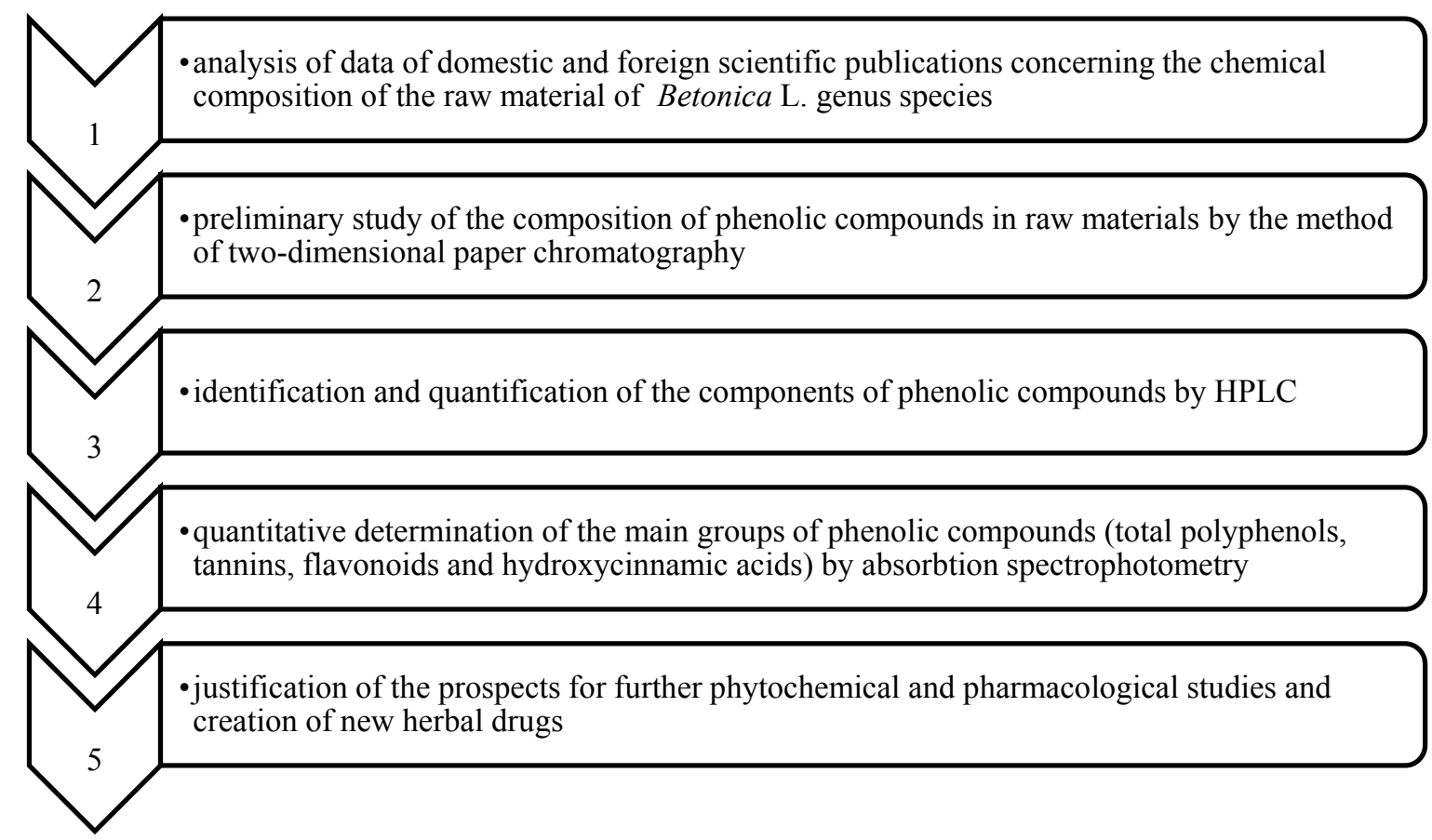

Fig. 1. Planning of the research

\section{Materials and methods}

\subsection{Plant material}

The raw material for the phytochemical study of phenolic compounds was the herb of Betonica peraucta and Betonica brachydonta harvested in the phase of mass flowering of the plant near the village of Bovshiv, Halych district, Ivano-Frankivsk region (GPS coordinates: 49.22580 northern latitude, 24.69623 east longitude) and the village of Dora, Nadvirna district, IvanoFrankivsk region (GPS coordinates: 48.48293 northern latitude, 24.55770 east longitude). The herb of Betonica consists of whole or cut, dried, flowering tops of stems, stem and basal leaves.

Harvesting and identification of morphologically related Betonica species was carried out under the guidance of Professor of Ivano-Frankivsk National Medical University Hrytsyk A. R. and with the assistance of Associate Professor of Biology and Ecology Department of Vasyl Stefanyk Precarpathian National University Shumska N. V. according to the botanical catalog [11]. The voucher specimens are stored at the Pharmacy Department of Ivano-Frankivsk National Medical University, Ivano-Frankivsk, Ukraine.
3.2. Investigation of phenolic compounds by paper chromatography

Separation of phenolic compounds was fulfilled by two-dimensional paper chromatography. $2.0 \mathrm{~g}$ of herb were extracted twice with $96 \%$ ethanol (1:10) and twice with $70 \%$ ethanol (1:10). The resulting alcohol extracts were combined, filtered, the ethanol was distilled off and the aqueous residue was treated with ethyl acetate. Ethyl acetate and aqueous fractions were, applied to "Filtrak FN-1" chromatographic paper and studied in the following solvent systems: $15 \%$ acetic acid and $n$-butanol acetic acid - purified water (4:1:2) (BAW). The dried chromatograms were studied in UV light before and after processing with ammonia vapor and $3 \%$ alcohol solution of aluminum chloride [12]. HPLC

\subsection{Investigation of phenolic compounds by}

Separation of the sum of phenolic compounds was carried out by HPLC on a high-performance liquid chromatograph Agilent Technologies 1200 (USA) with photometric diode-matrix detector UV-Vis G1315 equipped with a flow degasser G1322A, autosampler 
(automatic injector) G1329A, column thermostat G1316A in complex with personal computer with Agilent ChemStation software.

Separation of hydroxycinnamic acids, flavonoids, coumarins, tannins and their components was carried out by the reversed-phase chromatography using chromatographic column Discovery C18 sized $250 \times 4.6 \mathrm{~mm}$ with a sorbent (silica gel modified with octadecyl groups) and a grain diameter of $5 \mu \mathrm{m}$. The chromatographic conditions are given in scientific sources [13-15].

\subsection{Determination of the quantitative content} of phenolic compounds

Total polyphenols. Quantitative determination of total polyphenols was carried out by spectrophotometry in terms of pyrogalol according to the pharmacopoeial method (SPhU 2.0, Vol. 3 - pharmacopoeial monograph "Millefolii herba", p. 298) [13, 16, 17].

The content of total polyphenols (X, \%) in terms of pyrogallol was calculated using the formula (1):

$$
X \frac{62.5 \quad A_{1} \quad m_{2}}{A_{0} \quad m_{1}},
$$

where $A_{0}$ is the optical density of the reference solution; $A_{1}$ is the optical density of the test solution; $m_{1}$ is the weight of the raw material, $\mathrm{mg} ; m_{2}$ is the weight of the pyrogallol sample, mg.

Tannins. An accurate sample of the crushed raw material was placed in the 250 ml-capacity round bottom flask, $150 \mathrm{ml}$ of purified water was added and heated for $30 \mathrm{~min}$ on a water bath. Then the analysis is carried out according to the pharmacopoeial method - spectrophotometry in terms of pyrogallol (SPhU 2.0, Vol.1 - 2.8.14) [12].

The content of tannins (X, \%) in terms of pyrogallol was calculated using the formula (2):

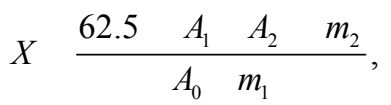

where $A_{0}$ is the optical density of the reference solution; $A_{1}$ is the optical density of the test solution; $A_{2}$ is the optical density of the test solution after the addition of pharmacopoeial standard sample skin powder; $m_{l}$ is the weight of the raw material, mg; $m_{2}$ is the weight of the pyrogallol sample, mg.

Total flavonoids. Determination of total flavonoids was carried out by absorption spectrophotometry in terms of apigenin, which is present in the herb of both investigated species of Betonica in the predominant amount. This method was modified and based on the reaction with $3 \%$ solution of aluminum chloride after preliminary hydrolysis of flavonoids-glycosides to the corresponding aglycones (SPhU 2.0, Vol.3, Monograph "Leonuri cardiacae herba") [13, 16-18].

The optical density of the obtained test and reference solutions was measured on a Specord M 40 spectrophotometer $30 \mathrm{~min}$ after preparation at a wavelength of $380 \mathrm{~nm}$ in a cuvette with a layer thickness of $10 \mathrm{~mm}$. To convert the content of flavonoids to apigenin we used the specific absorption rate $\left(\mathrm{E}_{1 \mathrm{~cm}}^{1 \%}\right)$ of the complex of apigenin with aluminium chloride at $380 \mathrm{~nm}$, which is 550 [18].

The content of total flavonoids $(\mathrm{X}, \%)$ in terms of apigenin and absolutely dry raw materials was calculated using the formula (3):

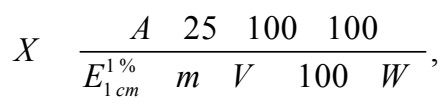

where $A$ is the optical density of the test solution; 25 is the volume of solution $\mathrm{B}, \mathrm{ml} ; 100$ is the volume of solution $\mathrm{A}, \mathrm{ml} ; E_{1 \mathrm{~cm}}^{1 \%}$ is the specific absorption of the complex of apigenin with aluminium chloride at $380 \mathrm{~nm}$, which equals $550 ; m$ is the weight of the sample of raw materials, $\mathrm{g} ; V$ is the volume of solution A used to prepare solution $\mathrm{B}, \mathrm{ml} ; W$ is the weight loss on drying, $\%$.

Hydroxycinnamic acids. Quantitative determination of hydroxycinnamic acids was carried out by the modified method of absorption spectrophotometry in terms of chlorogenic acid (SPhU 2.0, Vol.3, Monograph "Urticae folium") [13, 16, 17, 19].

The optical density of the obtained test and reference solutions was measured on a Specord M 40 spectrophotometer at a wavelength of $325 \mathrm{~nm}$ in a cuvette with a layer thickness of $10 \mathrm{~mm}$.

The content of total hydroxycinnamic acids $(\mathrm{X}, \%)$ in terms of chlorogenic acid and absolutely dry raw materials was calculated using the formula (4):

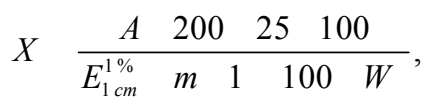

where $A$ is the optical density of the test solution; $m$ is the weight of the sample of raw materials, $\mathrm{g} ; E_{1 \mathrm{~cm}}^{1 \%}$ is the specific absorption of chlorogenic acid, which equals $531 ; W$ is the weight loss on drying, $\%$.

\subsection{Statistical analysis}

Student's t-test was used to statistically test the hypothesis of the probability of differences between the indicators of different groups. Statistical processing of the results was done by calculating the arithmetic mean, the average error of the arithmetic value, the reliability of the differences between results by the methods of variation statistics (SPhU 2.0, Vol.1 - 5.3, 5.3.N1) using Statistica 6.0 program and Word Excel. The number of repetitions of experiments (n) equals $9[12,20]$.

\section{Results}

The results of two-dimensional chromatography of aqueous and ethyl acetate fractions of extracts from the herb of Betonica peraucta (BPA and BPEA) and the herb of Betonica brachydonta (BBA and BBEA) are presented in Tables 1 and 2 and in Fig. 2 and 3.

Separation of the amount of phenolic compounds, identification and quantitative determination of individual components were done on the basis of the state enterprise "Ukrmetrteststandard" (Kyiv) by HPLC on a chromatograph Agilent Technologies 1200 
(USA) with photometric diode-matrix detector UV-Vis G1315 equipped with flow degasser G1322A, autosampler (automatic injector) G1329A and column thermostat G1316A in combination with a personal computer with Agilent ChemStation software.

Separation and determination of content of tannins and their components were carried out at the wavelength of $280 \mathrm{~nm}$ (Fig. 4).

Separation and determination of content of flavonoids and coumarins were carried out at the wavelengths of $255 \mathrm{~nm}$ and $340 \mathrm{~nm}$ (Fig. 5, 6).
Separation and determination of content of hydroxycinnamic acids were carried out at the wavelengths of $330 \mathrm{~nm}$ and $320 \mathrm{~nm}$ (Fig. 7, 8). The quantitative content of individual phenolic compounds in the herb of Betonica peraucta and Betonica brachydonta determined by HPLC is given in Table 3. Quantitative determination of content of the main groups of phenolic compounds, namely the total polyphenols, tannins, flavonoids and hydroxycinnamic acids, in the herb of Betonica peraucta and Betonica brachydonta was conducted by spectrophotometry according to pharmacopoeial methods (Table 4).

Table 1

Analysis of two-dimensional chromatograms of phenolic compounds of aqueous fractions of the extracts from the herb of Betonica peraucta and Betonica brachydonta

\begin{tabular}{|c|c|c|c|c|c|c|}
\hline $\begin{array}{c}\text { Spot } \\
\text { number } \\
\text { on the } \\
\text { chroma- } \\
\text { togram }\end{array}$ & $\begin{array}{l}\mathrm{Rf} \\
(15 \% \\
\text { acetic } \\
\text { acid })\end{array}$ & $\begin{array}{c}\mathrm{Rf} \\
(\mathrm{BAW} \\
(4: 1: 2))\end{array}$ & $\begin{array}{c}\text { Fluorescence } \\
\text { in UV light }\end{array}$ & $\begin{array}{l}\text { Fluorescence in } \\
\text { UV light after } \\
\text { processing with } \\
\text { ammonia vapor }\end{array}$ & $\begin{array}{c}\text { Color in visible } \\
\text { light after pro- } \\
\text { cessing with } 3 \% \\
\mathrm{AlCl}_{3}\end{array}$ & $\begin{array}{l}\text { Fluorescence in } \\
\text { UV light after } \\
\text { processing with } \\
3 \% \mathrm{AlCl}_{3}\end{array}$ \\
\hline \multicolumn{7}{|c|}{ BPA } \\
\hline 1 & 0.15 & 0.53 & - & Yellow & Yellow & Yellow \\
\hline 2 & 0.22 & 0.48 & Dark & Yellow & - & Yellow \\
\hline 3 & 0.25 & 0.54 & - & - & Yellow & Yellow \\
\hline 4 & 0.97 & 0.59 & - & - & Brown & Dark \\
\hline 5 & 0.94 & 0.69 & Dark & Yellow & Brown & Yellow \\
\hline 6 & 0.81 & 0.73 & Yellow & Yellow & Brown & Yellow \\
\hline 7 & 0.73 & 0.59 & Blue & Blue & - & Blue \\
\hline 8 & 0.68 & 0.75 & Blue & Blue & - & Blue \\
\hline \multicolumn{7}{|c|}{ BBA } \\
\hline 1 & 0.07 & 0.57 & Dark & Yellow & Yellow & Yellow \\
\hline 2 & 0.09 & 0.49 & Dark & Yellow & - & Yellow \\
\hline 3 & 0.15 & 0.49 & - & Yellow & Yellow & Yellow \\
\hline 4 & 0.97 & 0.57 & - & - & Brown & - \\
\hline 5 & 0.94 & 0.70 & Dark & Yellow & - & Yellow \\
\hline 6 & 0.86 & 0.58 & & - & Brown & - \\
\hline 7 & 0.80 & 0.66 & Blue & Blue & - & Blue \\
\hline 8 & 0.73 & 0.74 & Blue & Blue & - & Blue \\
\hline
\end{tabular}

Table 2

Analysis of two-dimensional chromatograms of phenolic compounds of ethyl acetate fractions of the extracts from the herb of Betonica brachydonta and Betonica brachydonta

\begin{tabular}{|c|c|c|c|c|c|c|}
\hline $\begin{array}{l}\text { Spot } \\
\text { number } \\
\text { on the } \\
\text { chroma- } \\
\text { togram }\end{array}$ & $\begin{array}{l}\mathrm{Rf} \\
(15 \% \\
\text { acetic } \\
\text { acid })\end{array}$ & $\begin{array}{c}\mathrm{Rf} \\
(\mathrm{BAW} \\
(4: 1: 2))\end{array}$ & $\begin{array}{l}\text { Fluorescence } \\
\text { in UV light }\end{array}$ & $\begin{array}{l}\text { Fluorescence in } \\
\text { UV light after } \\
\text { processing } \\
\text { with ammonia } \\
\text { vapor }\end{array}$ & $\begin{array}{l}\text { Color in visible } \\
\text { light after pro- } \\
\text { cessing with } 3 \% \\
\mathrm{AlCl}_{3}\end{array}$ & $\begin{array}{l}\text { Fluorescence in } \\
\text { UV light after } \\
\text { processing with } \\
3 \% \mathrm{AlCl}_{3}\end{array}$ \\
\hline \multicolumn{7}{|c|}{ BPEA } \\
\hline 1 & 0.13 & 0.54 & - & Yellow & Yellow & Yellow \\
\hline 2 & 0.22 & 0.54 & - & - & - & Yellow \\
\hline 3 & 0.94 & 0.71 & Dark & Yellow & - & Yellow \\
\hline 4 & 0.82 & 0.73 & Yellow & Yellow & - & Yellow \\
\hline 5 & 0.70 & 0.73 & Blue & Blue & - & Blue \\
\hline 6 & 0.10 & 0.40 & - & - & Yellow & Yellow \\
\hline 7 & 0.41 & 0.41 & Dark & Dark & - & Dark \\
\hline \multicolumn{7}{|c|}{ BBEA } \\
\hline 1 & 0.13 & 0.53 & - & Yellow & Yellow & Yellow \\
\hline 2 & 0.95 & 0.72 & Dark & Yellow & - & Yellow \\
\hline 3 & 0.84 & 0.75 & Yellow & Yellow & - & Yellow \\
\hline 4 & 0.75 & 0.76 & Blue & Blue & - & Blue \\
\hline 5 & 0.12 & 0.34 & - & - & Yellow & Yellow \\
\hline
\end{tabular}



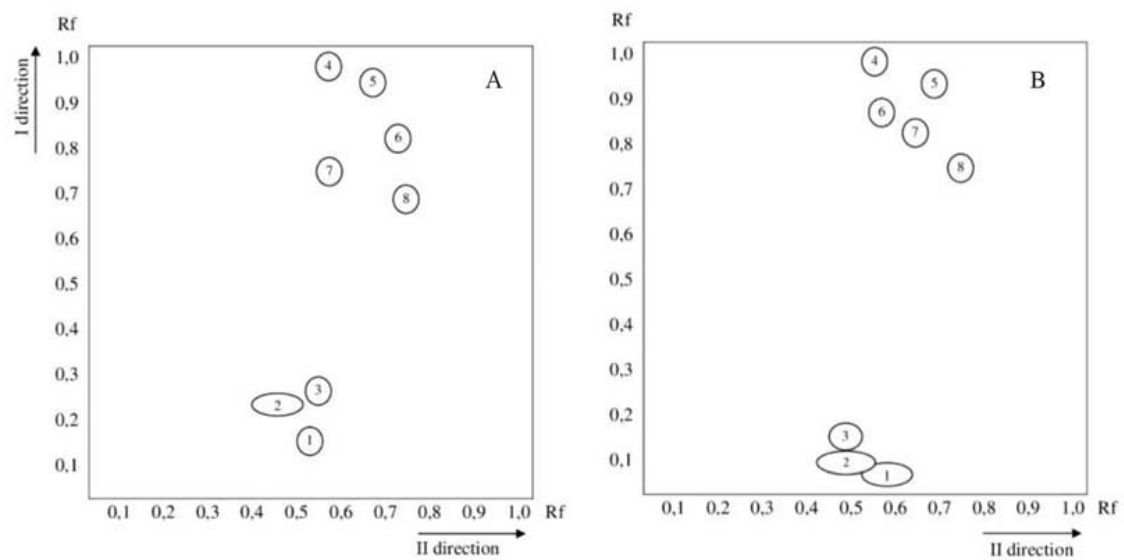

Fig. 2. Schemes of two-dimensional chromatograms of phenolic compounds of the aqueous fractions of the extracts from the herb of Betonica peraucta (A) and Betonica brachydonta (B). Solvent system: $15 \%$ acetic acid (I direction) and BAW (4:1:2) (II direction). Spots: 1-6 - flavonoids, 7-8 - hydroxycinnamic acids
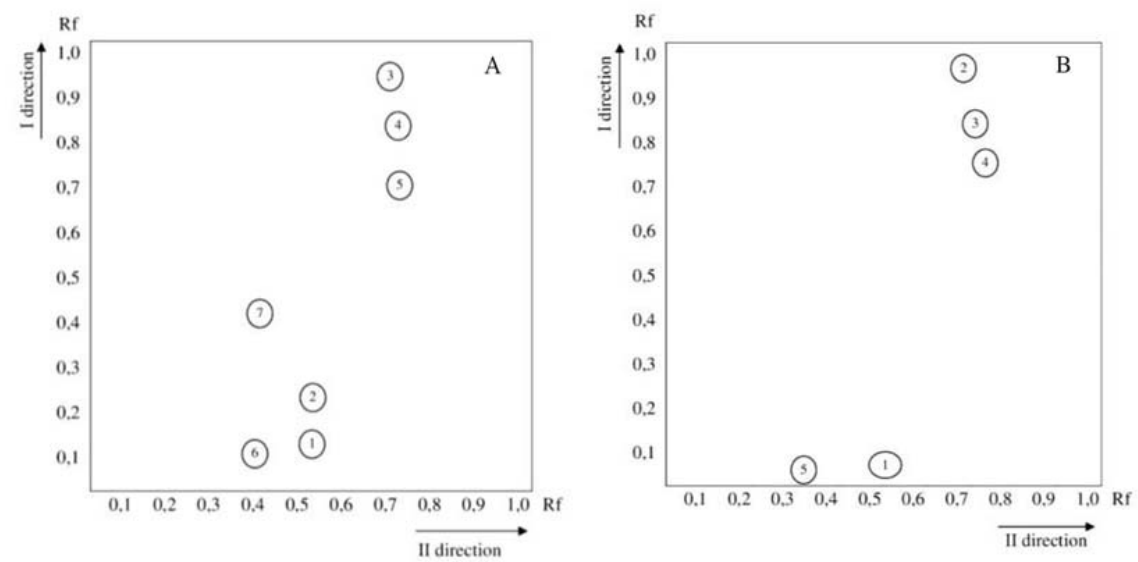

Fig. 3. Schemes of two-dimensional chromatograms of phenolic compounds of the ethyl acetate fractions of the extracts from the herb of Betonica peraucta (A) and Betonica brachydonta (B). Solvent system: $15 \%$ acetic acid (I direction) and

BAW (4:1:2) (II direction). Spots A: 1-4, 6, 7 - flavonoids, 5 - coumarin; spots B: 1-3, 5 - flavonoids, 4 - coumarin
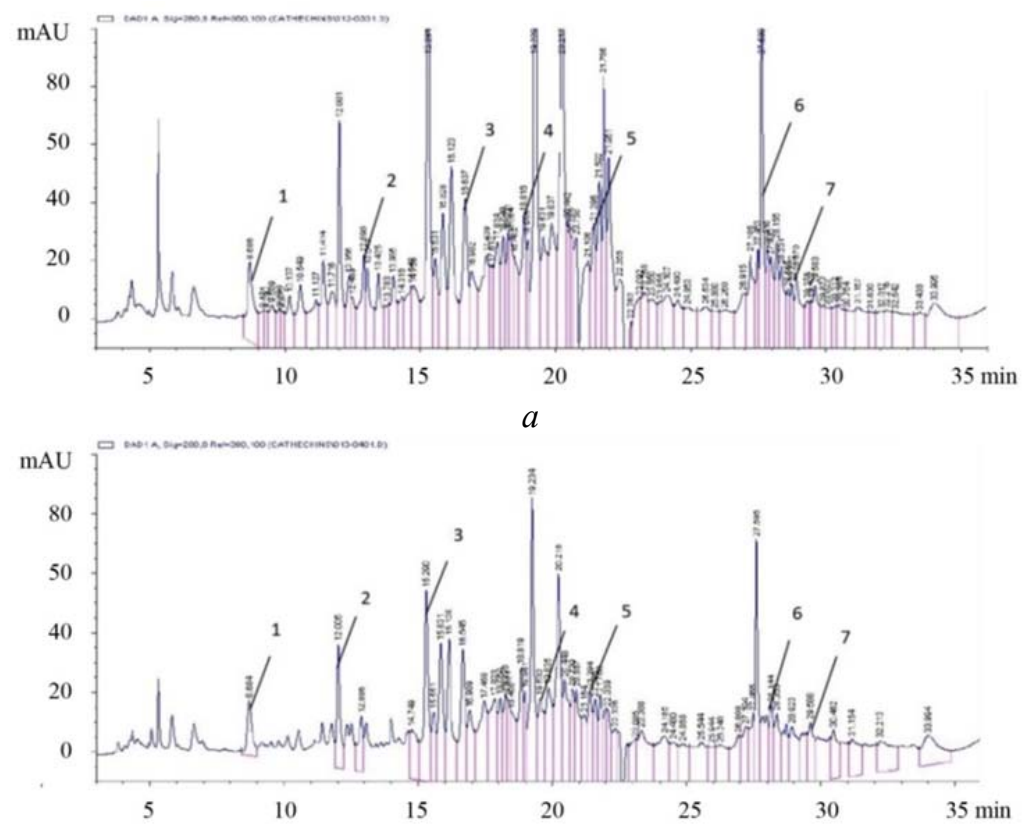

Fig. 4. Chromatogram of tannins and their components of $a$-Betonica peraucta; $b$ - Betonica brachydonta herb (wavelength $280 \mathrm{~nm}$ ); 1 - gallic acid, 2 - gallocatechin, 3 - epigallocatechin, 4 - catechin, 5 - epicatechin, 6 - epicatechin gallate, 7 - catechin gallate 

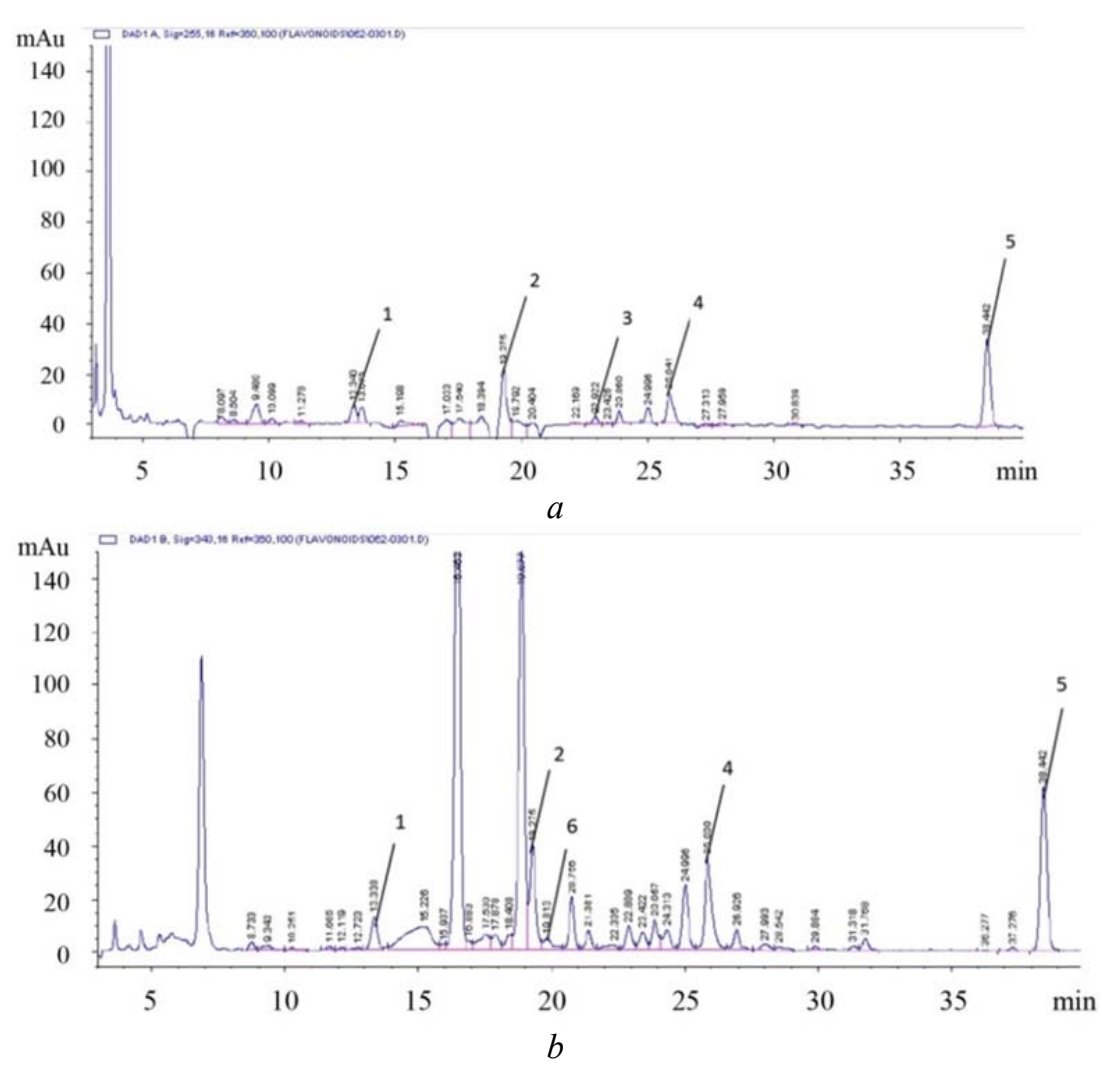

Fig. 5. Chromatogram of flavonoids of Betonica peraucta herb: $a$ - wavelength $255 \mathrm{~nm}$; $b$ - wavelength $340 \mathrm{~nm}$; 1 - rutin, 2 - luteolin, 3 - coumarin, 4 - isoquercitrin (quercetin-3-D-glucoside), 5 - apigenin, 6 - scopoletin

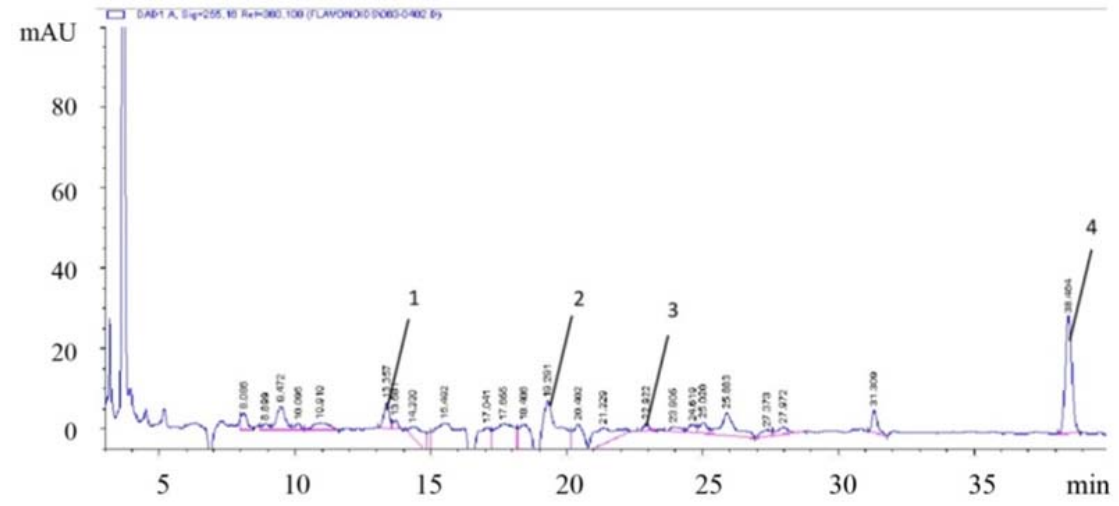

Fig. 6. Chromatogram of flavonoids of Betonica brachydonta herb (wavelength $255 \mathrm{~nm}$ ): 1 - rutin, 2 - luteolin, 3 - coumarin, 4 - apigenin

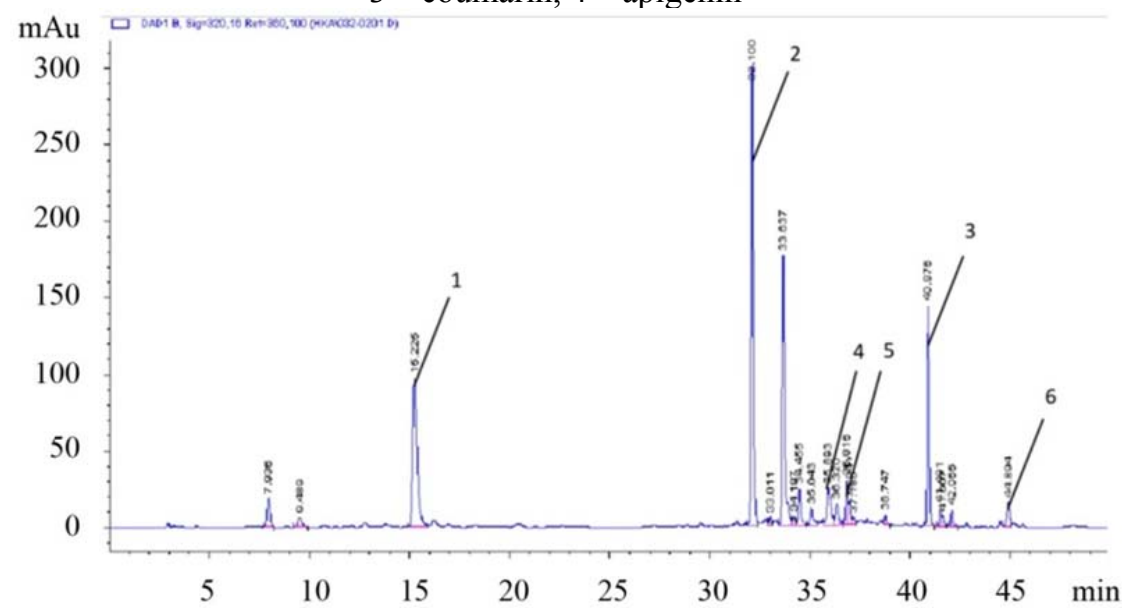

Fig. 7. Chromatogram of hydroxycinnamic acids of Betonica peraucta herb (wavelength $320 \mathrm{~nm}$ ): 1 - chlorogenic acid, 2 - rosemarinic acid, 3 - apigenin, 4 - caffeic acid, 5 - ferulic acid, 6 - $p$-coumaric acid 


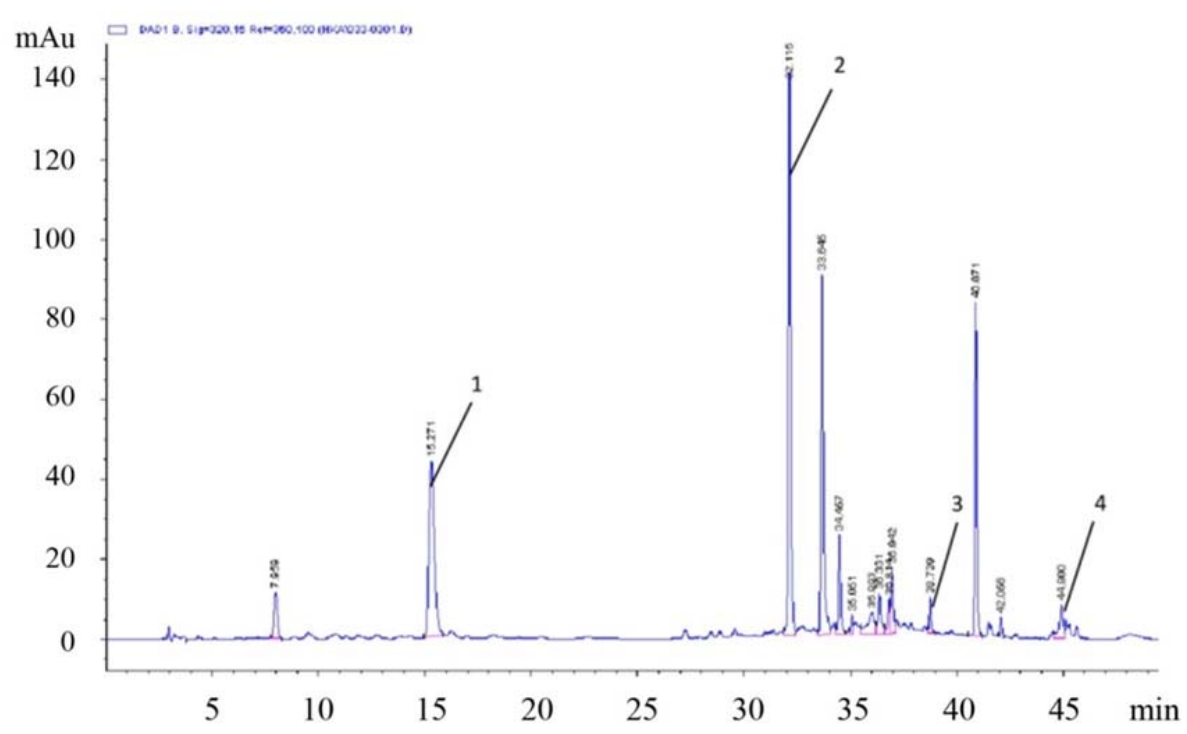

Fig. 8. Chromatogram of hydroxycinnamic acids of Betonica brachydonta herb (wavelength $320 \mathrm{~nm}$ ): 1 - chlorogenic acid, 2 - rosemarinic acid, 3 - apigenin, 4 - ferulic acid

The content of individual phenolic compounds in the herb of Betonica peraucta and Betonica brachydonta (HPLC method)

\begin{tabular}{|c|c|c|}
\hline \multirow{2}{*}{ Name of the compound } & \multicolumn{2}{|c|}{ Content of individual phenolic compounds, $\%$} \\
\hline & Betonica peraucta & Betonica brachydonta \\
\hline \multicolumn{3}{|c|}{ Tannins and their components } \\
\hline Gallic acid & 0.031 & 0.027 \\
\hline Gallocatechin & 0.318 & 0.149 \\
\hline Epigallocatechin & 2.423 & 0.520 \\
\hline Catechin & 0.175 & 0.084 \\
\hline Epicatechin & 0.136 & 0.105 \\
\hline Epicatechin gallate & 0.248 & 0.038 \\
\hline Catechin gallate & 0.063 & 0.058 \\
\hline \multicolumn{3}{|c|}{ Flavonoids } \\
\hline Apigenin & 0.176 & 0.051 \\
\hline Luteolin & 0.188 & 0.027 \\
\hline Rutin & 0.049 & 0.041 \\
\hline Isoquercitrin (quercetin-3-D-glucoside) & 0.056 & - \\
\hline \multicolumn{3}{|c|}{ Coumarins } \\
\hline Coumarin & 0.010 & 0.009 \\
\hline Scopoletin & 0.004 & - \\
\hline \multicolumn{3}{|c|}{ Hydroxycinnamic acids } \\
\hline$p$-Coumaric acid & 0.022 & - \\
\hline Caffeic acid & 0.060 & - \\
\hline Ferulic acid & 0.053 & 0.014 \\
\hline Rosemarinic acid & 2.142 & 1.253 \\
\hline Chlorogenic acid & 0.532 & 0.264 \\
\hline
\end{tabular}

Table 4

Quantitative content of phenolic compounds in the herb of Betonica peraucta and Betonica brachydonta

\section{Group of BAS}

Total polyphenols (in terms of pyrogallol, $760 \mathrm{~nm}$ )

Tannins (in terms of pyrogallol, $760 \mathrm{~nm}$ )

Flavonoids (after hydrolysis in terms of apigenin, $380 \mathrm{~nm}$ )

Hydroxycinnamic acids (in terms of chlorogenic acid, $325 \mathrm{~nm}$ )

Content of BAS, $\%, \bar{x} \quad \bar{x}, \mathrm{n}=9$

\section{Betonica peraucta $\quad$ Betonica brachydonta}

\begin{tabular}{|l|l|}
\hline $9.96 \pm 0.06$ & $4.82 \pm 0.08$ \\
\hline $1.62 \pm 0.02$ & $0.68 \pm 0.02$ \\
\hline $2.07 \pm 0.04$ & $1.13 \pm 0.01$ \\
\hline $7.01 \pm 0.03$ & $3.58 \pm 0.02$ \\
\hline
\end{tabular}




\section{Discussion}

By the method of paper chromatography taking into account the mobility of substances and their fluorescence in UV light before and after the treatment with chromogenic reagents it was determined that the herb of Betonica peraucta contains 15 compounds, and the herb of Betonica brachydonta contains 13 compounds of phenolic nature, which have been previously classified as flavonoids, hydroxycinnamic acids and coumarins (BPA spots: 1-6 - flavonoids, 7-8 - hydroxycinnamic acids; BPEA spots: $1-4,6,7$ - flavonoids, 5 - coumarin; BBA spots: 1-6 - flavonoids, 7-8 - hydroxycinnamic acids; BBEA spots: 1-3, 5 - flavonoids, 4 - coumarin).

By the HPLC method in the herb of the researched species were identified such tannins and their components as gallic acid, gallocatechin, epigallocatechin, catechin, epicatechin, epicatechin gallate and catechin gallate. In the herb of Betonica peraucta was determined the presence of following flavonoids: rutin, luteolin, isoquercitrin (quercetin-3-D-glucoside), apigenin, coumarin and scopoletin; such flavonoids as hyperoside, kaempferol, quercetin, umbelliferone were not identified. In the herb of Betonica brachydonta was determined the presence of following flavonoids: rutin, luteolin, apigenin and coumarin; such flavonoids as hyperoside, isoquercitrin, kaempferol, quercetin, umbelliferone and scopoletin were not identified. Among hydroxycinnamic acids in the herb of Betonica peraucta chlorogenic, rosemarinic, caffeic, ferulic and $p$-coumaric acids were identified; in the herb of Betonica brachydonta only chlorogenic, rosemarinic and $p$-coumaric acids were identified, but caffeic and ferulic acids were not detected.

The obtained HPLC results indicate that the composition of phenolic compounds of the herb of Betonica peraucta differs in the presence of the flavonoid isoquercitrin, hydroxycoumarin scopoletin, hydroxycinnamic acids: caffeic and $p$-coumaric. In addition, the content of individual phenolic compounds in the herb of Betonica brachydonta is much lower than in the herb of Betonica peraucta.

Among the components of tannins for both species epigallocatechin has the highest content $-2.423 \%$ and $0.520 \%$ in the herb of Betonica peraucta and Betonica brachydonta respectively; gallic acid has the lowest content $-0.031 \%$ and $0.027 \%$ in the herb of Betonica peraucta and Betonica brachydonta respectively. The dominant flavonoids in the herb of Betonica peraucta are luteolin $-0.188 \%$ and apigenin $-0.176 \%$; in the herb of Betonica brachydonta the dominant is apigenin $-0.027 \%$. Among hydroxycinnamic acids for both species rosemarinic acid is dominant $-2.142 \%$ and $1.253 \%$ in the herb of Betonica peraucta and Betonica brachydonta respectively; and the lowest content is determined for ferulic acid - $0.014 \%$ in the herb of Betonica brachydonta and for $p$-coumaric acid $-0.022 \%$ in the herb of Betonica peraucta.

It was determined by absorption spectrophotometry that the content of all groups of phenolic compounds is higher in the herb of Betonica peraucta. In particular, the content of tannins in the herb of Betonica peraucta is 2.38 times higher, hydroxycinnamic acids is 1.96 times higher and flavonoids is 1.83 times higher than in the herb of Betonica brachydonta.

Scientists from around the world have also studied the composition and quantitative content of polyphenolic compounds of Betonica L. genus species. Polish researchers (Bączek, K., Kosakowska, O., Przybył, J.-L., Węglarz Z.) have studied the dependence of the content of phenolic compounds in the purple betony herb on cultivation conditions. The highest content of tannins in the raw material of a two-year-old plant was $2.05 \%$ and in a three-year old plant $-2.91 \% .4$ hydroxycinnamic acids (chlorogenic, ferulic, caffeic and rosemarinic) and 5 flavonoid compounds (orientin, luteolin-7-glucoside, apigenin-7-glucoside, apigenin-3-glucoside, apigenin) were identified in the raw material. Caffeic acid and apigenin were dominant among these compounds [2]. Romanian scientists have found that the total phenolic content of the Betonica officinalis hydroalcoholic extract was $869.7 \pm 18.2 \mathrm{mg} \mathrm{GAE} / \mathrm{L}$ and total flavonoid content was $64.5 \pm 1.5 \mathrm{mg} \mathrm{QE} / \mathrm{L}$ [5]. In the Republic of Kosovo it was found that total phenols in the aboveground part of Betonica officinalis L. ranged from $2.29 \%$ to $8.05 \%$ in terms of caffeic acid, and the content of the total flavonoids ranged from $0.96 \%$ to $3.97 \%$ in terms of catechin [21]. Romanian researchers Imbrea, I., Butnariu, M., et al. studied the chemical composition of the herb of Stachys officinalis (L.) Trevis (syn. Betonica officinalis L.), which grows in southwestern Romania, and found that the content of polyphenols in terms of caffeic acid was $2.41 \%$, and flavonoids in terms of routine was $1.89 \%$ [22]. The flavonoid content of Betonica bulgarica Degen et Neič was studied by HPLC. Three flavonoids were found in significant amounts: rutin, quercetin and hispidulin. Rutin was in the largest quantity, followed by quercetin and hispidulin. The largest total flavonoid content was measured in leaves $\left(4941.7 \pm 345.1 \mathrm{mg} \cdot \mathrm{kg}^{-1} \mathrm{dm}\right.$ for rutin), followed by roots and flowers [4].

If we compare the data of foreign scientists and data obtained by us, we can conclude that the composition and quantitative content of phenolic compounds in different species of the Betonica L. genus differs, but not significantly. For example, rutin in Betonica peraucta accumulates in the smallest amount, but in Betonica bulgarica it is dominant [4]; p-coumaric acid has not been identified in Betonica officinalis, which grows in Poland [2] as well as in Ukrainian Betonica brachydonta, although it is present in Betonica peraucta; in Ukrainian species of Betonica genus rosemarinic acid is dominant, while in Polish species the dominant is caffeic acid [2], etc. This is caused by the diversity of this genus species, by the climatic conditions of their growth in the wild and the conditions of their cultivation, it also may depend on the methods used for analysis. However, there also is a certain pattern, in particular in the quantitative composition of the total polyphenols and flavonoids. For example, the content of total polyphenols in Betonica officinalis L. grawing in Republic of Kosovo ranged from $2.29 \%$ to $8.05 \%$, total flavonoids - from $0.96 \%$ to $3.97 \%$ [21] (in Ukrainian species total polyphenols ranged from $4.82 \%$ to $9.96 \%$ and total flavonoids ranged from $1.13 \%$ to $2.07 \%$ ). 
Study limitations. The number of standard substances was limited during the study of plant raw materials by HPLC method, that is why not all compounds of phenolic nature could be identified in the studied raw materials.

Prospects for further research. The results of phytochemical study of phenolic compounds of the herb of the studied species indicate that more promising for further research and for drugs development is the herb of Betonica peraucta. Taking into account its chemical composition we can predict that the resulting extract will have a pronounced anti-inflammatory, antioxidant or choleretic activity.

\section{Conclusions}

The composition of phenolic compounds in the herb of two morphologically similar species of Betonica L. genus growing in Ukraine was studied by the methods of paper chromatography, HPLC and absorption spectrophotometry.

Components of tannins, flavonoids, hydroxycinnamic acids and coumarins were identified by HPLC. Quantitative content of gallic acid, gallocatechin, epigallocatechin, catechin, epicatechin, epicatechin gallate, catechin gallate, rutin, luteolin, apigenin, coumarin, chlorogenic acid, rosemarinic acid and ferulic acid was determined in the herb of Betonica peraucta and Betonica brachydonta; in addition, isoquercitrin, scopoletin, caffeic and $p$-coumaric acids were detected in the herb of Betonica peraucta, unlike Betonica brachydonta.

The quantitative content of the amount of phenolic compounds in the herb of the studied species was determined by the method of absorption spectrophotometry. The content of phenolic compounds in the herb of Betonica peraucta and Betonica brachydonta is respectively: total polyphenols $-5.96 \%$ and $4.82 \%$, tannins $1.62 \%$ and $0.68 \%$, flavonoids $-2.07 \%$ and $1.13 \%$, hydroxycinnamic acids $-7.01 \%$ and $3.58 \%$.

As a result of phytochemical studies, it was found that the content of phenolic compounds is significantly higher in the herb of Betonica peraucta. Therefore, this species is promising for the creation of new herbal drugs.

\section{Conflict of interests}

The authors declare that they have no conflicts of interest.

\section{References}

1. Dimitrova-Dyulgerova, I., Merdzhanov, P., Todorov, K., Seymenska, D., Stoyanov, P., Mladenov, R., Stoyanova, A. (2015). Essential Oils Composition of Betonica officinalis L. and Stachys sylvatica L. (Lamiaceae) from Bulgaria. Proceedings of the Bulgarian Academy of Sciences, 68 (8), 991-998.

2. Bączek, K., Kosakowska, O., Przybył, J. L., Węglarz, Z. (2016). Accumulation of phenolic compounds in the purple betony herb (Stachys officinalis L.) originated from cultivation. Herba Polonica, 62 (2), 7-16. doi: http://doi.org/10.1515/hepo-2016-0007

3. Grytsyk, L., Grytsyk A., Sas I., Legin N., Kolyadjin T. (2016). Study of aminoacid composition of Betonica L., Sanicula L., and Astrantia L. Genera Species. The Pharma Innovation Journal, 5 (7), 46-48.

4. Tzanova, M., Grozeva, N., Gerdzhikova, M., Argirova, M., Pavlov, D., Terzieva, S. (2018). Flavonoid content and antioxidant activity of Betonica bulgarica Degen et Neič. Bulgarian Chemical Communications, 50 (C), 90-97.

5. Paun, G., Neagu, E., Moroeanu, V., Ungureanu, O., Cretu, R., Ionescu, E. et. al. (2017). Phytochemical analysis and in vitro biological activity of Betonica officinalis and Salvia officinalis extracts. Romanian Biotechnological Letters, 22 (4), 12751-12761.

6. Paun, G., Neagu, E., Albu, C., Moroeanu, V., Radu, G.-L. (2016). Antioxidant activity and inhibitory effect of polyphenolic-rich extract from Betonica officinalis and Impatiens noli-tangere herbs on key enzyme linked to type 2 diabetes. Journal of the Taiwan Institute of Chemical Engineers, 60, 1-7. doi: http://doi.org/10.1016/j.jtice.2015.10.005

7. Paun, G., Neagu, E., Moroeanu, V., Albu, C., Ursu, T.-M., Zanfirescu, A. et. al. (2018). Anti-inflammatory and antioxidant activities of the Impatiens noli-tangere and Stachys officinalis polyphenolic-rich extracts. Revista Brasileira de Farmacognosia, 28 (1), 57-64. doi: http://doi.org/10.1016/j.bjp.2017.10.008

8. Uritu, C. M., Mihai, C. T., Stanciu, G.-D., Dodi, G., Alexa-Stratulat, T., Luca, A. et. al. (2018). Medicinal Plants of the Family Lamiaceae in Pain Therapy: A Review. Pain Research and Management, 2018, 1-44. doi: http://doi.org/10.1155/2018/7801543

9. Hrytsyk, A., Sas, I. (2017). Hostra toksychnist ta antyeksudatyvna aktyvnist ekstraktiv travy bukvytsi perebilshenoi (Betonica peraucta Klok.) ta bukvytsi korotkozuboi (Betonica brachydonta Klok.). Farmakom, 4, 29-33.

10. Sas, I. (2019). Doslidzhennia sedatyvnoi aktyvnosti ekstraktiv vydiv rodu Bukvytsia - Betonica (L.). Farmakom, 4, $23-27$.

11. Dobrochaeva, D. N., Kotov, M. I., Prokudin, Yu. N., Barbarich, A. I. (1999). Opredelitel vysshyh rasteniy Ukrainy. Kyiv: Fitosotsyotsentr, 548.

12. Derzhavna Farmakopeia Ukrainy. Vol. 1 (2015). Kharkiv: Derzhavne pidpryiemstvo «Ukrainskyi naukovyi farmakopeinyi tsentr yakosti likarskykh zasobiv», 1128.

13. Starchenko, G., Hrytsyk, A., Raal, A., Koshovyi, O. (2020). Phytochemical Profile and Pharmacological Activities of Water and Hydroethanolic Dry Extracts of Calluna vulgaris (L.) Hull. Herb. Plants, 9 (6), 751. doi: http://doi.org/10.3390/plants9060751

14. Krivoruchko, E., Markin, A., Samoilova, V., Ilina, T., Koshovyi, O. (2018). Research in the chemical composition of the bark of sorbus aucuparia. Ceska a Slovenska Farmacie, 67 (3), 113-115.

15. Koshovyi, O., Raal, A., Kovaleva, A., Myha, M., Ilina, T., Borodina, N., Komissarenko, A. (2020). The phytochemical and chemotaxonomic study of Salvia spp. growing in Ukraine. Journal of Applied Biology \& Biotechnology, 8 (3), 29-36. doi: http://doi.org/10.7324/JABB.2020.80306

16. Derzhavna Farmakopeia Ukrainy. Vol. 3 (2014). Kharkiv: Derzhavne pidpryiemstvo «Ukrainskyi naukovyi farmakopeinyi tsentr yakosti likarskykh zasobiv», 732.

17. Ilina, T., Kashpur, N., Granica, S., Bazylko, A., Shinkovenko, I., Kovalyova, A. et. al. (2019). Phytochemical Profiles and In Vitro Immunomodulatory Activity of Ethanolic Extracts from Galium aparine L. Plants, 8 (12), 541. doi: http://doi.org/10.3390/plants8120541

18. Shestakova, T., Belonohova, V., Petrychenko, V. (2016). Spektrofotometricheskiy metod opredeleniya soderzhaniya flavonoidov v trave Veronica chamaedrys (Scrophulariaceae). Meditsynskiy almanah, 1 (41), 127-130. 
19. Štefan, M. B., Vuković Rodríguez, J., Blažeković, B., Kindl, M., \& Vladimir-Knežević, S. (2013). Total Hydroxycinnamic Acids Assay: Prevalidation and Application on Lamiaceae Species. Food Analytical Methods, 7 (2), 326-336. doi: http://doi.org/10.1007/s12161013-9630-8

20. Thiese, M., Arnold, Z., Walker, S. (2015). The misuse and abuse of statistics in biomedical research. Biochemia Medica, 25 (1), 5-11. doi: http://doi.org/10.11613/BM.2015.001

21. Hajdari, A., Mustafa, B., Franz, Ch., Novak, J. (2010). Total flavonoids, total phenolics and antioxidant activity of Betonica officinalis L. from Kosovo. Acta Horticulturae, 860, 75-80. doi: http://doi.org/10.17660/actahortic.2010.860.8

22. Imbrea, I., Butnariu, M., Nicolin, A., Imbrea, F., Prodan, M. (2011). Valorising the Species Stachys officinalis (L.) Trevis. from South-Western Romania. Research Journal of Agricultural Science, 43 (2), 198-203.

Received date 15.01.2021 Accepted date 24.02.2021 Published date 28.02.2021

Iryna Sas, PhD, Assistant, Department of Pharmacy, Ivano-Frankivsk National Medical University, Halytska str., 2, Ivano-Frankivsk, Ukraine, 76018

E-mail: mamatolika09@gmail.com

Andriy Grytsyk, Doctor of Pharmaceutical Sciences, Professor, Head of Department, Department of Pharmacy, Ivano-Frankivsk National Medical University, Halytska str., 2, Ivano-Frankivsk, Ukraine, 76018 E-mail: grycyk@ukr.net

Taras Koliadzhyn, PhD, Assistant, Department of Pharmacy, Ivano-Frankivsk National Medical University, Halytska str., 2, Ivano-Frankivsk, Ukraine, 76018

E-mail: taraskolyadjin@gmail.com

Oleh Koshovyi, Doctor of Pharmaceutical Sciences, Professor, Head of the Department, Department of Pharmacognosy, National University of Pharmacy, Pushkinska str., 53, Kharkiv, Ukraine, 61002

E-mail: oleh.koshovyi@gmail.com 